\title{
Learning Management Systems and Instructional Design:
}

Best Practices in Online Education

Yefim Kats

Chestnut Hill College, USA 
Managing Director:

Editorial Director:

Book Production Manager:

Publishing Systems Analyst:

Development Editor:

Assistant Acquisitions Editor:

Typesetter:

Cover Design:
Lindsay Johnston

Joel Gamon

Jennifer Yoder

Adrienne Freeland

Joel Gamon

Kayla Wolfe

Lisandro Gonzalez

Jason Mull

Published in the United States of America by

Information Science Reference (an imprint of IGI Global)

701 E. Chocolate Avenue

Hershey PA 17033

Tel: 717-533-8845

Fax: 717-533-8661

E-mail: cust@igi-global.com

Web site: http://www.igi-global.com

Copyright ( 2013 by IGI Global. All rights reserved. No part of this publication may be reproduced, stored or distributed in any form or by any means, electronic or mechanical, including photocopying, without written permission from the publisher. Product or company names used in this set are for identification purposes only. Inclusion of the names of the products or companies does not indicate a claim of ownership by IGI Global of the trademark or registered trademark.

\section{Library of Congress Cataloging-in-Publication Data}

Learning management systems and instructional design : best practices in online education / Yefim Kats, editor. pages $\mathrm{cm}$ Includes bibliographical references and index.

Summary: "This book provides an overview on the connection between learning management systems and the variety of instructional design models and methods of course delivery, offering a useful source for administrators, faculty, instructional designers, course developers, and businesses interested in the technological solutions and methods of online education"-Provided by publisher.

ISBN 978-1-4666-3930-0 (hardcover) -- ISBN 978-1-4666-3931-7 (ebook) -- ISBN 978-1-4666-3932-4 (print \& perpetual access) 1. Internet in higher education--Case studies. 2. Education, Higher--Computer-assisted instruction--Case studies. 3. Web-based instruction--Design. I. Kats, Yefim.

LB2395.7.L44 2013

378.1'7344678--dc23

2012050502

British Cataloguing in Publication Data

A Cataloguing in Publication record for this book is available from the British Library.

All work contributed to this book is new, previously-unpublished material. The views expressed in this book are those of the authors, but not necessarily of the publisher. 


\title{
Chapter 17 \\ Immersive Virtual Environments to Facilitate Authentic Education in Logistics and Supply Chain Management
}

\author{
Torsten Reiners \\ Curtin University, Australia \\ Lincoln C. Wood \\ Auckland University of Technology, New Zealand \& Curtin University, Australia
}

\begin{abstract}
This chapter will cover our current research concerning developing and trialling immersive environments as an innovative and authentic approach to teaching and learning in Logistics and Supply Chain Management, incorporating seamlessly integrated assessment and feedback. Developed educational and assessment tools will allow students to demonstrate that they have successfully applied theoretical knowledge in real contexts and developed appropriate skills before entering the workforce. Greater authenticity allows students to experience different roles and exposes them to multiple business cases over supply chains that, in reality, span the globe. The project addresses the inauthentic pedagogical approaches in current classroom and distance-learning environments, and will propose a methodology that utilises existing technologies. The simulation will combine emerging technologies to represent multiple problem dimensions into one space; enabling students to observe, engage, interact, and participate in self-guided or group-based learning scenarios; receiving instant, multi-perspective, media-rich feedback to support their learning; and enabling further iterative scenario-based training.
\end{abstract}

\section{INTRODUCTION}

Throughout the Australasian higher education sector student numbers rose rapidly during the 1990s while the study population gained greater diversity (Martin \& Karmel, 2002). This increas-

DOI: 10.4018/978-1-4666-3930-0.ch017 ingly diverse student body has been positive as the increasing diversity allows students to better "represent ideal social forums for promoting cultural understanding; fostering tolerance of diversity; discovering alternative ways of thinking; and developing inter-cultural skills" (Volet \& Ang, 1998, p. 6). However, the increase in student numbers and diversity also creates challenges for instruc- 
tors. Simultaneously, there is increasing pressure to make better use of resources while ensuring that students are well-prepared for work. This has led to many instructors having a focus on being able to "get as many students as possible to meet professionally/academically acceptable levels of performance at as high a level as we can", given available resources (Buckridge \& Guest, 2007, p. 144). A key method that has been used to solve this problem has been increasing engagement with students during the learning process, often through the incorporation of active learning techniques in classrooms. Here, 'what happens' is important, but there is also a critical need to consider 'how it happens'; i.e., regarding the achievement of learning objectives (Terenzini, Cabrera, Colbeck, Bjorklund, \& Parente, 2001).

Educators and course designers need to be aware that "a dual focus on both content and delivery is necessary" to ensure effective learning in supply chain classes (Wood \& Reefke, 2010, p. 78). Academics and industry partners also report the need to find a common denominator in preparing students for real-world experience. One example is the usage of educational games and activities in logistics and supply chain management (L\&SCM) classes. The use of these activities enable students to understand the concepts and the learning objectives more effectively when they have been given time to learn and understand the rules and how the game works. This can circumnavigate the need for specific instruction on these subjects and this form of active learning ensures "practices empower them in class and create new opportunities for interaction outside class" (Maruyama, Moreno, Gudeman, \& Marin, 2000, p. 78). One of the best-known and accepted supply chain simulations is the Beer Game, used to demonstrate and analyse the bullwhip effect and the impact that this has on supply chains (Lee, Padmanabhan, \& Wang, 1997; Sterman, 1989). Even though such simulations may be successful, they still frequently fail to reach high levels of authentic- ity as they are relatively simple computer-based simulations or operate using pens, paper, boards and tokens. While they are more interactive than learning from a textbook, the approach still lacks the connection with real-life scenarios due to the inherent abstraction of concepts embedded in the simulation.

This chapter will explore improved engagement through active learning, feedback opportunities, multiple iterations and repetition, authentic education, and immersive environments. We describe a conceptual framework for the development and implementation of a multi-iteration scenariobased training environment with emphasis on joint learning opportunities in an authentic learning environment; i.e., for authentic learning of required working skills. The potential value and need for such situations is outlined, followed by a development of several research propositions suggested by the discussions.

\section{Engagement with Students through Active Learning}

One of the key methods to improve engagement is through designing and structuring classroom activities so they incorporate more interactivity and opportunities to speak with students (Wood \& Reefke, 2010). There are many examples of educational activities being suitable for logistics and supply chain management classes. Examples may be found within books such as 'Games and Exercises for Operations Management' (Heineke $\&$ Meile, 1995) and 'Implementing Lean Manufacturing Techniques' (Page, 2004). The use of these activities enable students to understand the concepts and the learning objectives more effectively when they have been given time to learn and understand the rules and how the game works. This can circumnavigate the need for specific instruction on these subjects and this form of active learning ensures that "practices empower them in class and create new opportunities for interaction 
outside class" (Maruyama et al., 2000, p. 78). Activities perceived as fun and playful are more likely to elicit attention and achieve educational results, which can be enhanced by gamification principles (discussed later in the chapter), amplifying the effect of active learning.

The ability to engage in a class, with peers, has been linked to the success of students (Gurin, Dey, Hurtado, \& Gurin, 2002) and has been shown to reduce the adjustment period for new students (Zhang, Sillitoe, \& Webb, 1999). However, in the past, implementation of high levels of engagement with staff members has required additional resource investment by the educational institution. It is not clear what cost implications these approaches may have.

\section{Feedback Opportunities}

The two types of feedback can be classified as formative or summative. Formative feedback is "information communicated to the learner that is intended to modify his or her thinking or behavior for the purpose of improving learning" (Shute, 2008, p. 154). Providing feedback to students is crucial for educational purposes; however, it does consume a great deal of time (Ferns, 2011), is frequently frustrating (Bailey \& Garner, 2010), and can cause high levels of stress (Hogan, Carlson, $\&$ Dua, 2002). There are other ways of providing feedback and it can be the case that activities can be structured within the classroom to incorporate elements of Blooms Taxonomy (Krathwohl, 2002) to provide opportunities for further feedback, particularly when the process of teaching has been carefully observed (De Vita \& Case, 2003). Improving the teaching process requires significant levels of "passion and enthusiasm, combined with an interactive and structured teaching approach, can greatly enhance the learning experience of students and lead to higher levels of attendance and academic achievement" (Revell \& Wainwright, 2009, p. 221).
Effective and useful feedback will observe the following seven principles (Nicol \& MacfarlaneDick, 2006, p. 205):

1. Helps clarify what good performance is (goals, criteria, expected standards);

2. Facilitates the development of self-assessment (reflection) in learning;

3. Delivers high quality information to students about their learning;

4. Encourages teacher and peer dialogue around learning;

5. Encourages positive motivational beliefs and self-esteem;

6. Provides opportunities to close the gap between current and desired performance;

7. Provides information to teachers that can be used to help shape teaching.

Modern technological methods and computerised approaches improve provision of feedback by allowing assessment to "include rapid formative feedback to students, reduced marking load for staff, and a closer match between the assessment and learning environments" (Ricketts $\&$ Wilks, 2002, p. 478). Such a decrease in the submission-to-feedback lead time is identified by Dreher (2006) as being particularly crucial in contemporary education.

Other options involve the self-assessment approach, which is perceived favourably by students as they believe it helps to consolidate their knowledge (Ibabe \& Jauregizar, 2010). Such approaches can also be integrated with existing pedagogical means. Taras (2003) has shown that "student self-assessment with integrated tutor feedback is one efficient means of helping students overcome unrealistic expectations and focus on their achievement rather than on the input required to produce their work" (p. 562). It is becoming increasingly important to have a 'multidimensional view of feedback' to support effective education particularly as online and 
blended learning environments increasingly form a core part of educational practices (Schwartz \& White, 2000).

\section{Authentic Learning}

There are already simulations that can be used in the classroom environment to aid education and the specific teaching of logistics and supply chain management principles. One of the most commonly well-known and accepted simulations is the Beer Game (Lee et al., 1997; Sterman, 1989). This has traditionally been played using a boardbased approach; a form that originated with the developers at MIT and has been used for many decades. One drawback with this approach is that students often struggle and make mistakes with calculations, particularly where they get to the backorders and mathematics become slightly more complicated. By the time a student realises that there is a problem with the calculations it is usually too late to correct this easily; instead, significant lecturer input is required to unravel the problem and put the team back to where they should be. One solution has been the use of electronic versions of the Beer Game that has allowed them to progress without the difficulties of board-based approaches. It also allows rapid compilation of statistics for use in class discussions and enables current examples to be used in discussions with a class (Wood \& Reefke, 2010).

Another innovative simulation is "The Fresh Connection" simulation, developed by the Dutch firm Involvation, which is being used by several universities and corporations around Australia and Europe (Cotter, Forster, \& Sweeney, 2009). The simulated firm is modelled on a real freshfruit juice manufacturing company and students work in teams of four players, each with separate supply chain related responsibilities (managers of sales and distribution, purchasing, operations, and supply chain). Decisions require trade-offs be made over functional lines. There is a high level of detail with a reasonable volume of data and analysis available to the students. Furthermore, they are able to compress time as each round progresses the game, with their decisions fixed, for a 26-week period. The interface is through the computer monitor where they are given a dashboard, an area where they have options that they can change; and a reporting screen, where they can analyse data and understand the impact of their last changes.

Such simulations do, however, fail to reach high levels of authenticity. While they are more authentic than learning from a textbook, the approach still lacks the connection with real life examples due to an inherent level of abstraction. The students are still faced with information presented in reports, with much information easily accessible and ready for digestion by the decision-makers.

\section{Gamification and Virtual Space}

Despite the diverse discussion about Second Life and the past gold rush hype to exploit the virtual space, 3D environments are still growing markets (forecast by KZero (2009) to be US \$9b value in 2013; (Gartner Research, 2011); see IEEE VW Standard Working Group (2012) for an overview). Virtual Worlds are described as "online environments that have game-like immersion and social media functionality without game-like goals or rules. At the heart is a sense of presence with others at the same time and in the same place" (Constable, 2008). Communication, interaction, and exploration of the immersive space is facilitated by so-called avatars; in-world representations of people controlled by the user. In contrast to games with predefined aims for the player, virtual worlds provide space for user-generated content allowing for more flexibility in creating scenarios. While the main stream of research in virtual worlds focuses on entertainment, education is strongly represented with implementations from different disciplines to enhance distance education, refine pedagogical models, provide specialised environments for communication and role-play 
for teaching and learning support, and visualise tangible and intangible artefacts for demonstration and inspection (for example, see Boerger \& Tietgens, 2013).

The proposed n-dimensional immersive virtual environment (nDiVE), with its focus on L\&SCM, enables different projects demonstrating that virtual spaces are feasible and beneficial in increasing awareness of interlinked processes, internal and external influences on effectiveness and efficiency, and how problems can influence the process. Preliminary implementations in Second Life executed by the authors demonstrate a small interactive supply chain for students; consisting of a container terminal (representing the link to the supplier in terms of delivered items per time period), manufacturer (bottle filling machine), and customer (Wriedt, Reiners, \& Ebeling, 2008).

There are still arguments about the success and need about virtual spaces like Second Life. Following the hype, many projects were terminated, others accessible without any further development or even maintenance, while many educational projects still have strong supporters. The progress of Web 2.0 and mobile technology strengthened the entertainment and gaming industry, providing advanced technology and channels for reaching out to customers. In this context, technologies like 3D@home, Augmented Reality and 3D graphic engines on mobile devices, social networking, and virtual collaboration pushed gaming from a niche market for younger adults to a mass market with acceptance in a broader social stratum. Gaming is a growing market with a potential of US $\$ 2.8 \mathrm{~b}$ in 2016 (Peterson, 2012) and proliferation of 60\% at "midsize-to-large organisations deploying at least one gamified application by 2021" (Burke, 2011). In this process, non-game, real-world contexts are enhanced with technology and mechanics from games to engage, encourage, focus, and guide users addressing the predisposition in gaming (Radoff, 2011). Mechanics of gamification include rewarded achievements (badges), leader boards, progress bars, or competitive challenges (Bajdor \& Dragolea, 2011); augmenting tasks with motivational objectives to fight against the inner temptation of quitting. Gaming has demonstrated that tasks must be specifically designed with environments that are capable of engaging and motivating students. Under these circumstances, even though the level of abstraction is still high, students are more likely to learn effectively (Lainema \& Hilmola, 2005; Rosenberg, 2006). Active learning and engagement can be further enhanced through injecting 'fun, play, and passion' (SAP, 2012) into a task. In educational or training programs "serious games" are used to make the learning process more engaging (Landers \& Callan, 2011, p. 399). It is seen by Deloitte as a 'disruptor' in the technology trends (Deloitte, 2012), which may change how many firms structure non-training related tasks. Groh (2012) pointed out that gamification has not yet lived up to its hype and despite the promise of an almost-natural methodology for engagement; "proper scientific studies about the benefits as well as the side-effects of gamification" have to be conducted to demonstrate the long-term benefits.

\section{Authentic education and the role of an immersive simulated environment}

Educational research tends to remain at the level of theoretical academic debate and frequently stops short of supporting results that are brought into practice to solve real problems. This has been a major weakness of traditional e-learning and classroom instruction. Unfortunately, it is still common practice for universities and tertiary institutions to invest in expensive IT solutions rather than renewing pedagogical practices for increased sustainability. Studies indicate that new technology is often used to reinforce industrial-era working methods and practices; it tends to promote "learning from" rather than "learning with" technologies (Herrington, Reeves, \& Oliver, 2010). 'Authentic education' refers to learning in environments that provide learners with opportunities to exercise 
realistic work practices, methods, and cognitive processes in authentic situations; receive valuable feedback; and to make use of authentic sources and materials (Herrington \& Herrington, 2006; Herrington et al., 2010).

Authentic education remains the exception rather than the rule at universities, a situation largely due to perpetuated teaching traditions, a lack of knowledge, and misconceptions about authentic learning. Other hindrances to the operational shift and implementation of current research include: socialising within traditional roles, instructional design, infrastructure, and administrative challenges. Authentic education encompasses all areas including design, creation, acquisition, and presentation through to evaluation and assessment methods and strategies.

Teaching L\&SCM in a classroom restricts access to the immersive experience required to appreciate and fully comprehend the subject. While abstract textbook visualisations can be supported by photos and videos, the sensation of dimension and complexity that emerges from logistical processes cannot be captured. Students report that they feel inadequately prepared for their professional career path and that expectations of the industry require stronger consideration in the curriculum (Holt, Mackay, \& Smith, 2003). Industry supports these claims, concurring that recent graduates lack requisite skills, are often ignorant of the workings of company cultures, and are uncertain how to transfer their university-acquired theoretical knowledge to effective practice; in short, the students require a more authentic learning experience to enable them to attain an adequate level of training (Lombardi, 2007).

Educators require support from instructional designers to create and apply authenticity to their lectures; i.e., in mapping the real-world problem space into a controlled environment for teaching and learning. Reflecting the focus of this chapter, the emphasis is on skills training and joint learning opportunities in an authentic n-dimensional, multiiteration, scenario-based, training environment; with ' $n$ ' being used to refer to a number greater than the traditional three spatial dimensions; e.g., product attributes like cost, size, or quality. In some areas like education and health, the exploration of multi-dimensional spaces has already proceeded to a level where virtual experiences are an integral component of the curriculum. Nevertheless, in L\&SCM, the following principles are not yet applied holistically or systemically; but, may enhance the outcome of the education further, provide new and industry-focused skills, and prepare learners for the real world.

\section{Learning in Realistic Contexts}

Through scenario-based simulated environments and assessments, learners have the opportunity to acquire the knowledge to react appropriately. The assessment work includes the design and development of strategies for specific roles before they are needed. The design work focuses on the creation of extreme conditions not possible to experience in real life due to safety of participants or complexity of systems; e.g., inducing stress or pressure during the decision making process. In reality, events or activities are frequently separated from consequences by both time (as they occur late after the event) and space (effects may be felt a distance away from the events). As an example, an error made by a supplier in the aerospace industry may cause the shipment to be late to a manufacturing site, causing effects in one firm that may never been seen by workers that made the initial error, and would occur so much later than the workers would never had made the connection between cause and effect. As a consequence, identification and rectification of the causes of problems is challenging, which may cause product failure in the marketplace leading to loss of life.

\section{Compression of Time and Space to Generate a Holistic Experience}

The use of simulation allows compression of a globally distributed supply chain into a restricted space so that the entire supply chain can be ob- 
served in a single setting. Similarly, activities can be 'sped up' to enable a full range of activities to be simulated multiple times with variations. Such elements are not readily available with traditional constrained classroom-based approaches to L\&SCM education; however, the fast-forward functionality is common in most simulation-based games to bypass the process of development or effects of strategies. The aforementioned Fresh Connection, Supply Chain Game by Responsive. net (see also, Feng \& Ma, 2008), or Supply Chain Risk Management Game (Kuijpers, 2009), all exemplify the compression of time and space, yet not encompassing the other principles completely.

\section{Reality vs. Abstraction}

In classrooms, abstract visualisations or descriptions (enriched by photos and videos) are most commonly used to explain complex constructs or interdependent processes in a supply chain. While field trips provide a glimpse into L\&SCM reality, they are not holistic and must be combined with other artefacts such as diagrams. The abstraction level is even higher if extraordinary scenarios are constructed; events such as power failures or machine breakdowns cannot be readily tested on an operational production line.

\section{Immersive Authentic Environment}

An environment to train people through multiple simulated experiences can provide students with control of a supply chain and force them to ensure survival/safety of people or preservation of the environment in the face of an emergency. Students can become involved in a range of business processes that would normally be distributed around the world, providing an end-to-end perspective. This provides greater holistic understanding of the overall system in a way that cannot otherwise be achieved. Interfaces with high levels of authenticity enable interaction within the nDiVE system.

\section{Scenario-based Training}

Students can use the multi-iteration and scenario-based elements of $\mathrm{nDiVE}$ to experience 'catastrophic failures' and examine the impact on multiple firms in the supply chain. Images fail to capture the dynamic impact of problems as they ripple over interconnected firms. 'Time is money' and the iterated training under pressure allows better judgements to be made under stress in situations that closely match real circumstances in business. An added benefit is that a student can be placed into a range of interconnected roles so that they can experience the same events from multiple perspectives, providing insight into real trade-offs and other functional or departmental perspectives on a single event.

\section{Secure and Safe Experience}

Safety for the learners is often difficult to ensure on field trips. L\&SCM environments are inherently dangerous with heavy equipment, noise, and distraction combining to present significant risks to visitors. Site visits often involve very small groups with extensive safety briefings and safety clothing/equipment, and student movement limited to well-defined 'safe zones'. Using nDiVE, learners may be exposed to a variety of circumstances and situations that would otherwise be unavailable, or unsafe, in a real environment.

\section{Improved Student Participation and Flexibility over Multiple Locations}

Traditional disadvantages faced by off-campus students in comparison to face-to-face students are eliminated as all students participate in the same space. To afford greater equity and flexibility of access, especially for off-campus students, interactivity and automated bots (non-human characters) must be incorporated to populate the scenario and create a dynamic atmosphere for the learners. 
Bots are scripted to simulate humans performing specific processes. Actions by learners can trigger corresponding responses from bots. For example, after a student uses a container bridge to place a container on the back of a truck, the container may be transported to a warehouse by the bot.

\section{SUPPLY CHAIN EDUCATION}

A structured learning process is necessary to maximise the learning opportunity from a study tour and Porth (1997) recognised that there are three phases, refined by Do (2006) as: preexperience activities involving student-generated research about the topic; the student-centric experiences during the activity; and post-activity capture and consolidation of student learning, as modes of experiential learning (Kolb, 1984). This three-phase approach is still valuable with nDive, where there is pre-experience preparation, on-site guidelines to maximise and remind about learning outcomes, and post-experience discussions. In much the same way a similar, structured methodical approach can be used (Figure 1). Students are exposed to situations to help them gradually gain the skills required, replete with post-exercise reinforcing learning.
Developed educational and assessment tools will allow students to demonstrate that they have successfully applied theoretical knowledge in real contexts and developed appropriate skills before entering the workforce. As an example-a student may be training to use a 'straddle carrier' (or, 'van carrier' in Germany). These large vehicles are used only within the confines of Ports and are used to manoeuvre and shift containers for storage after removing them from the vessel. Such a learning environment in a Port could be structured to involve the four elements.

1. Role Play: Here the student would discuss some scenarios that may be important in operating a straddle carrier. They would need to talk through some key situations and how they would respond, interacting with other classmates while receiving feedback from the instructor. The student would be within the real working environment but working towards an understanding of the role of a straddle carrier and what the key principles are behind operating it. Through observation, key lessons can be learned. These can be pointed out in a structured observational session, where each principle could be recorded or displayed in a way that it is isolated and decontextualised.

Figure 1. The supply chain education wheel showing the progression of a student through a range of learning tasks and styles

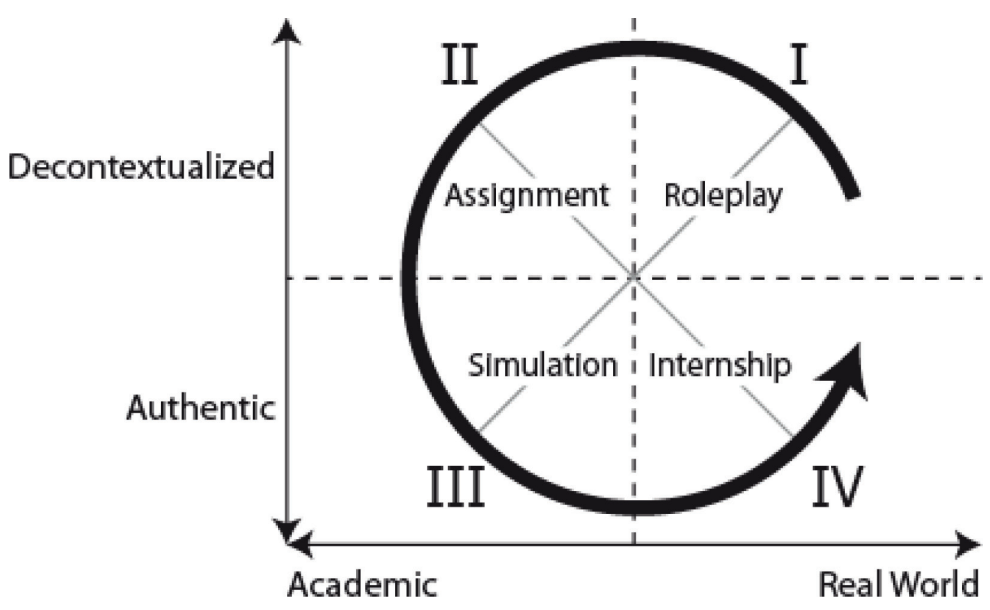


2. Assignment: The student would sit a test or assignment, whereby they would need to demonstrate that they understand key elements of how to operate a straddle carrier. This is 'decontextualised' so each element or challenge would be examined independently of others.

3. Simulation: The student would be immersed in a simulated training environment, to help them understand and 'grow into' the concepts through experience. Here, multiple challenges are incorporated simultaneously, increasing the realism, but structured so that there are key learning objectives. The student may, for example, be required to operate a straddle carrier within a mock area set aside and not in current use in the port. The simulators could then devise a series of hazards and challenges for the student to navigate successfully. Factors are under the instructor's control, allowing increasingly challenging combinations of factors to be experienced by the student.

4. Internship: Here, the student operates a real straddle carrier over a period of time, in an actual operating environment. This enables the student to demonstrate competence under realistic situations (such as heavy rain, or fog, which may be difficult to simulate). This period would still be conducted under close supervision, but many variables would be outside of the instructor's control.

During each of these steps there is a learning experience that may be structured to ensure that there is a seamless integration of assessment and feedback to support the user learning experience. In all the circumstances, activities are intended to be 'supervised' by qualified and experienced instructors, so there is always feedback available. In many cases, the feedback may be formative only, to help the user gain appropriate adjustments to their responses and capabilities, preparing them for later, summative, assessments.
Where the experiences are conducted in a virtual environment the interaction with the environment can be carefully planned and controlled by instructors. Many interactions can be automated with pre-scripted bots. Users are then able to use machinima and the automated interactions for self-directed learning and also for subsequent instructor-led evaluation that lead to guided learning/polishing.

nDiVE acts as a bridge between real-life experiences and the academic world, rather than a replacement for either (see Figure 2). As different types of knowledge or understanding are required for each, it is the ability to bridge and combine these that provides value to the user. By incorporating the ability to 'do' (from the real world) with the ability to understand theory (from the academic world), nDiVE works to join, or stitch together these two perspectives on learning. Hanna (2000, p. 203) noted that "traditional students, whose work experience is limited, often do not grasp the practical significance of theories covered in business classes." It is also important to bridge these elements as "[i]solating domain knowledge and compartmentalising itinto independent disciplines de-contextualises the source of knowledge" (Do, 2006, p. 3), reducing the learning experience for the students.

Working in this manner, nDiVE brings simulation and a virtual environment to logistics and

Figure 2. nDiVE as a method to draw the 'real world' and the 'academic world' together by increasing the overlap

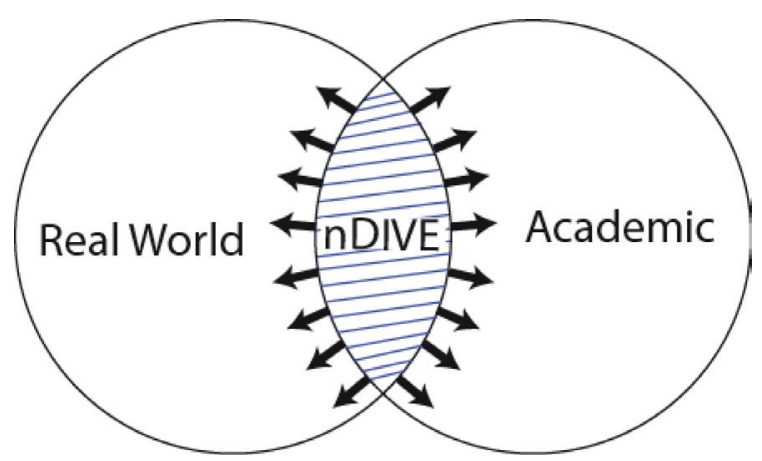


supply chain management education. It opens the door to a more realistic learning environment. It can be used much as existing simulations are used in business systems, such as flight simulators, as a dedicated environment for training and staff development. It provides the users with experiences that can only be obtained throughinteraction with the real world, but in an environment where the user is free to experiment, try, and play in a way that they cannot hurt themselves, harm anyone, or damage any expensive or sensitive equipment. It enables users to interact with a set environment and scenario multiple times to conduct multiple experiments, in a way in which they are unable to do in the real world. This may involve dangerous, rare, or tricky environments, which cannot be effectively replicated in a real-world environment. In a flight simulator this may include emergency landings on water; in nDiVE this may include the management of a toxic chemical spill within a manufacturing environment. Thus, we replicate much of the functionality of a flight simulator, but in a much broader context, and throughout the entire supply chain.

\section{nDIVE: n-DIMENSIONAL IMMERSIVE ENVIRONMENT}

nDiVE facilitates immersive simulation to experience real-world scenarios and develop skills in a risk-free environment (Figure 3 shows some screenshots of relevant scenarios). Simulated training is common, where errors by operators can cause degradation of human life (e.g., flight simulators for pilots or the use of special manne-

Figure 3. Screenshots from Second Life projects illustrating 'components' of previous projects (a container terminal, production facility, and controller platform for decision making) that can be linked in nDiVE to represent a system-wide supply chain (Burmester et al., 2008; Wriedt et al., 2008).
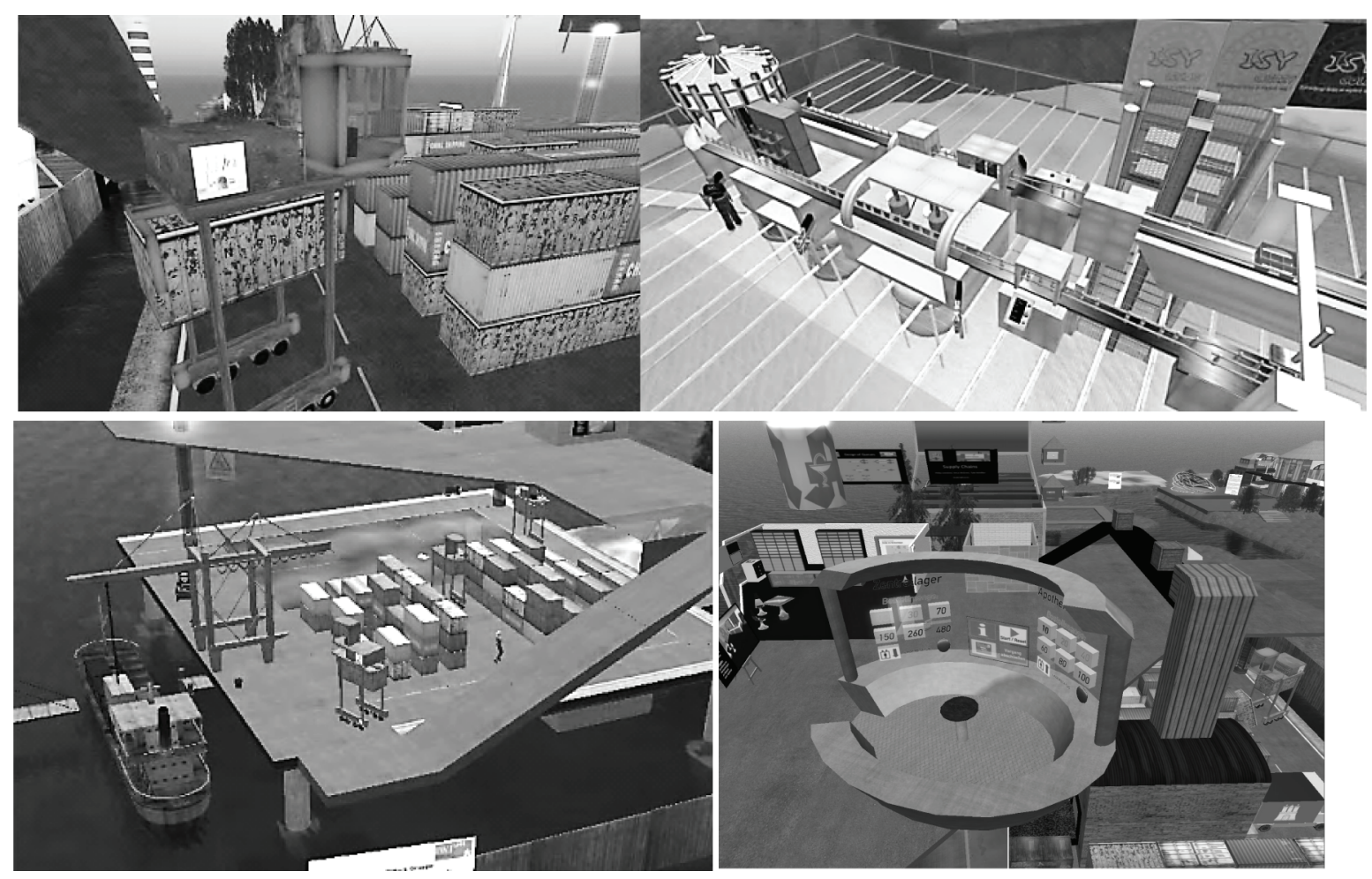
quins designed to emulate medical emergencies to train medical staff); however, it is less common in L\&SCM to experience realistic, visualised simulation, and immediate interaction in the context of teaching and learning.

\section{Compression of Space and Time}

Supply chains can be relatively small, such as local farmers supplying markets near the villages where produce is grown; they can also be large, spanning vast geographic distances and involving significant complexity and many interconnected companies (Figure 4). Demonstration of supply chain principles in a small, local, supply chain may be possible, yet many graduates from supply chain programmes will eventually work within more substantial supply chains, with only passing similarities to the small, local supply chains.

One of the most significant challenges for contemporary supply chains, spanning continents and perhaps dozens of key firms, is that it is challenging and expensive for a student to understand the key principles and activities and how they are linked together. As a result, what is often presented in the class is an abstracted view of the supply chain, in an inauthentic setting.
The 'study tour' is one option to increase authenticity in learning as it helps students to understand context and practical significance, and is becoming increasingly viable and important in contemporary tertiary education. While "the study tour helps to bridge the gap between business theory and practice" (Porth, 1997, pp. 198-199), such tours are not going to going to be a component of all supply chain educational programmes, as:

In some geographic areas it is possible to tour a real supply chain including several stages in the creation of value, following the very same path as materials [. . .]. In other geographic areas, a modified supply chain tour may be the only option. A modified supply chain tour includes multiple stages in the creation of value, but all of the individual facilities are not directly linked in customer-supplier relationships. (Hanna, 2000, p. 205)

The practical difficulties, costs, and maintenance of learning objectives all represent significant difficulties that are identified by Hanna (2000, pp. 204-205) and which must be overcome. Another weakness of study tours and physical

Figure 4. The 'real world' has supply chains spanning vast geographic regions which makes it difficult for students to understand the interconnected subtleties of the supply chain; in the 'virtual world' a student can see the different components of the supply chain and observe how they interact.

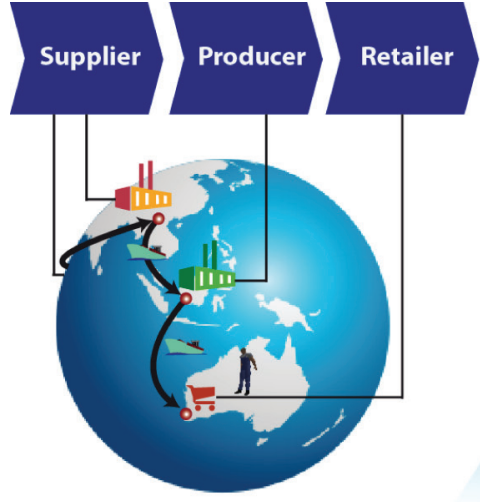

Real World

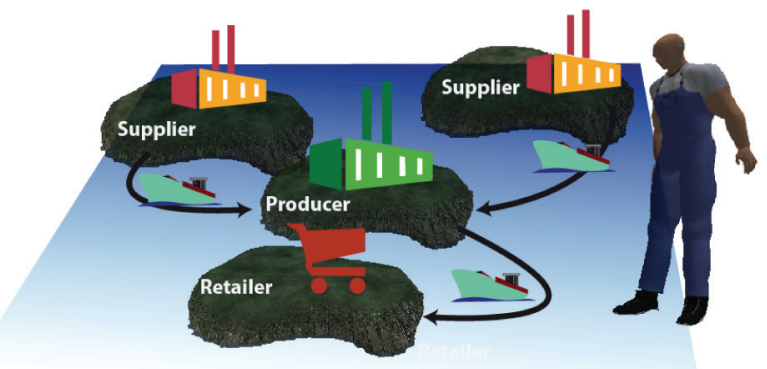

Virtual World 
visits is the limitation of being able to access appropriate information to understand appropriate responses by managers This may be remedied in an nDiVE environment by allowing a user to access information that would otherwise be proprietary and accessible only to a small range of users, and bring this up and overlay it on an image. As a result, users will be able to observe dimensions such as costs, risks, probability of errors, or value-added towards completion.

Similar challenges are present for the 'time' dimension. With learning periods generally being limited to a semester of around ten weeks, manufacturing lead times of two or three weeks and transport durations of around six weeks between continents soon exceed the scope of a learning period. Board games and simulations overcome these restrictions by compressing the periods of time when there are few events of interest in the scenario. In case of the supply chain, the visualisation of the transport methods between the manufacturer and customer is important, in case of a shared vessel, yet it is not relevant to observe every stop on its route but merely have an overview of the overall journey. The same principle applies to the level of detail where the exact path every transhipment or movement of goods might be irrelevant to the case of observing long-term supply chain developments. Careful simulation of large supply chains in the nDiVE environment may resolve the challenges of the globally-spread supply chain through the compression of space and time in a virtual environment. With the exception of vertically integrated firms, most supply chains use components or inputs from different countries or distant geographic regions (such as the supply chain shown in the 'real world' in Figure 4), highlighting the practical utility of the approach.

\section{Safety, Damage, and Costs}

The safety of individuals and stakeholders is becoming increasingly important within most societies and communities. This has resulted in significant workplace occupational health and safety (OSH) legislation, supported in the workplace through intensive training programmes and documentation of practices. The act of prohibiting particular actions, without understanding, may not successfully deter undesirable (in this case, unsafe) behaviours. Thus, the ability to simulate different scenarios in multiple environments, and enable users to actively explore the consequences of their actions, allows users to make their own conclusions about safety. Users are able to experiment, try new actions in response to set scenarios, and view the outcomes of the interaction.

A local focus may involve the use of equipment like forklifts. On a forklift it is difficult to know precisely how fast 'too fast' is. In working environments, users frequently push acceptable safety boundaries. A scenario can be simulated to allow a user to operate a forklift with a full (and heavy) load, allowing them the opportunity to go at different speeds until a calamitous accident occurs, whereupon the user can view the impact of loads toppling, perhaps also observing how it knocks over further stacks or storage areas, causing significant system-wide damage that exceeds what they may have anticipated. Obviously, replicating this scenario is possible in a physical environment yet it would be costly and potentially hazardous; the nDiVE simulation would be preferable.

A systemic focus for a scenario may involve issues such as the quality of components over a supply chain. This may demonstrate to a user how quality problems embedded within the manufacturing of a single component may, when it is used in a larger assembly several firms down in the supply chain, cause significant problems. An example may be where quality is compromised in the manufacture of a single widget, causing an oil-spill or gas leak when it is used by a firm downstream. These impacts spread and the seriousness amplifies as the effects 'ripple' downstream along the supply chain towards the consumers. The ability to observe these outcomes, due to timecompression, allows a user to rapidly gain feedback 
about the choices they make. Such a scenario is impossible to replicate in a physical environment for workers in firms that are upstream. The costs of such a quality problem are significant.

Such scenarios may enable users to experiment with a range of actions, receiving feedback each time on the outcomes associated with their actions. This will improve their appreciation of the complexity of the supply chain and the interrelated nature of the various components, while at no time compromising the safety of the learners themselves. The simulated environment also removes the costs involved with training in a physical environment, while also reducing the potential damage to real items or pieces of equipment, which may be extremely expensive in manufacturing environments.

The use of nDiVE presents a favourable return on the investment in the development and use of the system when the cost of accidents that may be avoided post training are considered. Development and use of these environments and creation of supporting pedagogical materials offers the opportunity to capture significant health and safey benefits to organisations that use the system, as well as benefiting wider groups of stakeholders. Users will be able to develop skills and capabilities that will, in turn, ensure a safer working environment and fewer supply chain catastrophes. This is achieved with the aid of low-cost environments and components as inputs, ensuring that improved safety and enhanced protection of life is assured with minimal investments. The environment and scenarios are easily transferred to other situations to enable teachers to develop new functional scenarios, creating a generalisable framework that can produce functionally-reusable, yet novel models, at low-cost. TUEV Nord has demonstrated that training in virtual worlds is effective: a pilot study produced savings in excess of US $\$ 140,000$ in ten months and experimental results show that a day's training for 20 workers engaged in safetyload training using virtual environments can save up to US $\$ 60,000$ compared to physical training
(Boerger \& Tietgens, 2013). Examination of fatalities attributed to problems with training indicate that a lack of training, employee absenteeism during training periods, or a failure to adhere to training are key factors involved in $92 \%$ of these fatalities (MacCarron, 2006). It may be inferred that casual workers would benefit significantly from fast and effective virtual training. Therefore, nDiVE supports the opportunity for broad community support in the generation of a cost-effective solution to health and safety challenges which impact on many stakeholders.

\section{The nDiVE Library and Modular Architecture}

The sheer magnitude of a supply chain makes a comprehensive simulation impossible and undesirable to implement. It is impossible due to the complexity and it is undesirable from a learning perspective, as it is still valuable to be able to isolate key activities with defined and clear learning objectives and learning outcomes. As a result, the nDiVEenvironment acts in a similar way to a set of encyclopaedias, where each volume is connected to those on either side in a logical manner, but each is a separate volume by itself. This provides the user with the ability to 'remove' a particular volume and 'dive into' it to learn what it holds. In much the same way, an nDiVE user will be able to select an appropriate scenario or 'slice' of the supply chain, from the 'library' or catalogue of the linked scenarios, remove it, and immerse themselves within this scenario (Figure 5).

Everything can be made ready in the cube and for a learning experience a subject is chosen to immerse the learners in. This allows a student to 'zoom in' on a particular focus, problem, or section of the supply chain. Within each section a student could further zoom into a particular situation or element of the wider supply chain. To experience it, we open it.

Such an approach has the additional benefit of allowing relatively complex intra-firm organi- 
Figure 5. A multi-dimensional perspective which allows a various 'segment' of the supply chain to be selected for further, in-depth, investigation

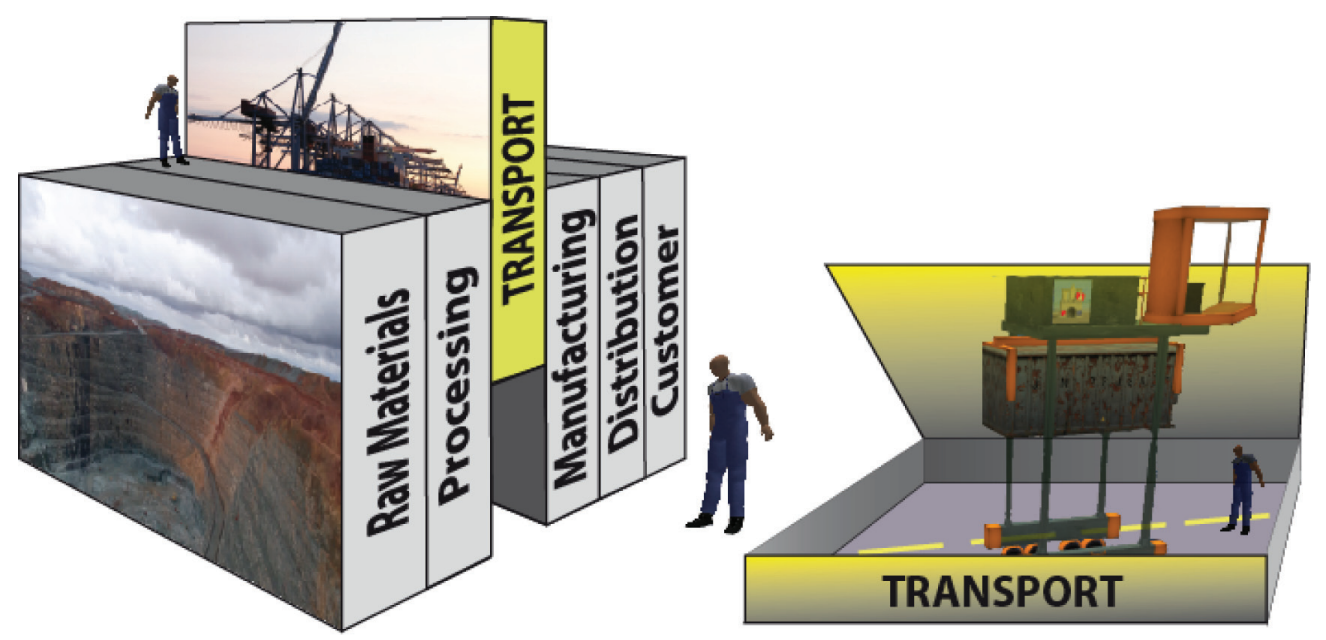

sational principles to be presented to the student. Students would be able to understand the interactions between multiple functions within different manufacturing environments. Even within the environments such interactions may be difficult to observe fully. As an example, users would be able to observe how more effective new product development can occur through complex and otherwise invisible inter-functional interactions ( $\mathrm{L}$. Wood \& Lu, 2008). This could be accomplished through 'zooming in' on any given production line (such as that shown in Figure 3) and examining different setups and arrangements of equipment and departmental interactions that are required to bring the production line to this particular configuration.

The segments represented in Figure 5 as slices can be programmed as a series of interconnected modules, creating an entirely modular architecture for the nDiVE environment. Key benefits include the ability for students or development groups to concurrently tackle and develop modules to be placed within the supply chain, with the opportunity for the development to proceed as a student competition. If there is a module that is not created, it can be represented as a 'black box'; an incomplete module that users are not able to actively view or directly interact with. Instead, materials or information flows into that module would be 'transformed' as they would with a fully implemented module, but this would be based only on the underlying algorithms and there would be no virtual representation of any flows or activities (Figure 6). This element of the overall architecture enables a full supply chain to be designed at the outset before being progressively populated by modules. If modules are not supplied, the presence of black boxes enables the remainder of the nDiVE environment to still function effectively; however, the environment would fail to deliver the full benefit to the users.

It is important to note that this method pulls each module out of context for the purposes of the learning activity. However, students are able to continue through one activity through to another. This is similar to the present approach in university education that compartmentalises many subjects. We follow this pedagogical tradition but also allow a student to re-contextualise and break down the barriers of each compartment. Furthermore, while maintaining context over multiple modules the student is able to observing how the 
Figure 6. A 'black box' can be used to in the place of a completed module that students can interact with, without significant reduction in the overall value of the linked supply chain.

a. A completed module for 'transport' that is embedded in a flow of materials and information along the supply chain. Here students are able to interact with the module directly with results flowing into other upstream and downstream modules.
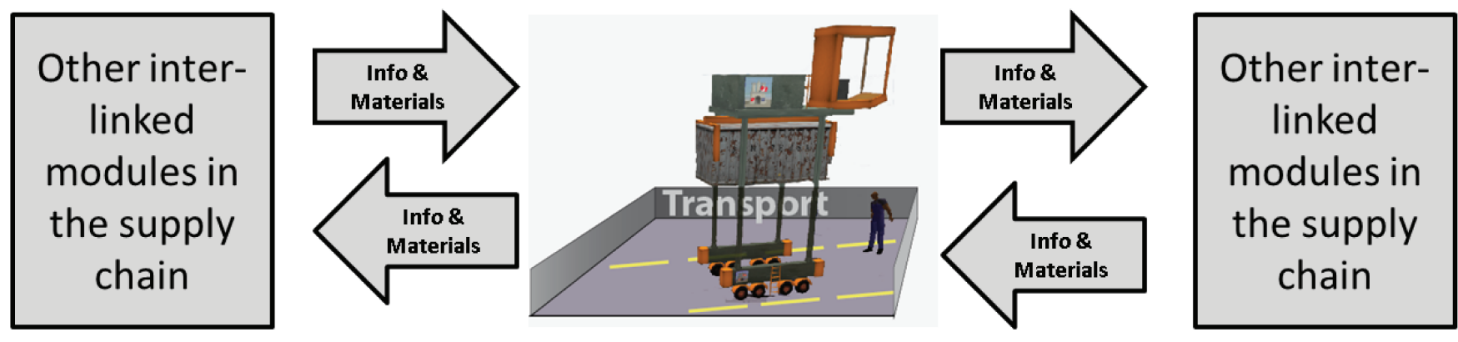

b. A 'black box' is used where there is insufficient time or resources to complete a fully interactive module along the supply chain. Users cannot interact but the supply chain, as a whole, can be modelled successfully. Materials and information are still passed through the 'black box' and are treated as though they have passed through a completed module, whereby they are transformed appropriately using algorithms, and the results are passed upstream and downstream along the supply chain as required.
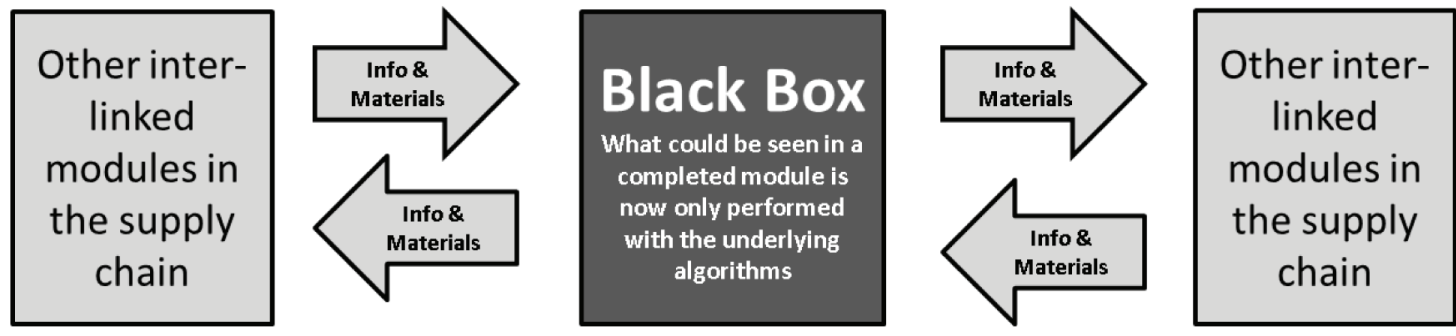

flow of materials or information develops. It quickly becomes clear how decisions or activity upstream develop into different outcomes downstream.

While this connection of modules occurs, students are able to perceive different dimensions. These can be the additional costs and how they are developing in relation to the expected final cost of a given product. As an example, some manufacturing processes will add significant per-unit costs. In contrast, some logistics activities (such as intercontinental shipping) may add relatively little per-unit costs. Similarly, some activities will significantly enhance the overall quality of a product, or introduce more opportunities for errors or defects to occur. The ability to replay scenarios in the modules allows students to understand the complexity and interaction of these dimensions in a way that is not otherwise possible with existing pedagogical approaches.

\section{Multiple Iterations and Recordings}

One of the big benefits of an immersive environment and the ability to manage activities virtually is the ability to work through multiple iterations of the scenario. This means the student is able to select one learning opportunity and approach this multiple times using multiple approaches. This will allow a student to run through a variety of different theories or possible approaches, observing the impact, and learning from this outcome before attempting the scenario again to improve their results. 
The key element is the use of a recording mechanism within the immersive environment. The use of lecture recordings has been noted is very valuable for students who have English as an additional language as it allows students to replay recordings over to pick up on nuances of spoken communication (L. C. Wood \& Reefke, 2010). In a similar manner, immersive environments allow the recording of activities and present a similar opportunity to many students to observe repeatedly until they understand the dynamics. It would allow students to 'go back in time' and revisit the scenario that they have worked through, evaluating and inspecting their own results. Using multiple iterations of specific scenarios coupled with availability of different data displays, students are able to integrate new experiences into their knowledge through repeated experiment (Slone, 2009).

Benefiting from greater authenticity allows students to experience different roles and exposes them to multiple business scenarios over supply chains that, in reality, span the globe. Some authenticity is deliberately excluded, as we increase visibility of multiple dimensions simultaneously. The simulation will combine emerging technologies to represent multiple problem dimensions into one space; students can observe, engage, interact, and participate in self-guided or group-based learning scenarios; receiving instant, multi-perspective, media-rich feedback to support their learning; and enabling further iterative scenario-based training.

\section{Instructional Benefits}

Instructors are provided with an overview and aggregation of data on student learning. Automatic collection of statistics and data enable reports to be generated so that administrators or instructors are able to understand whether students have experienced all available modules, or what percentage of coverage they have achieved, over the entire supply chain. This can enable targeted encouragement to be provided to students to complete the exercises available.
Control can also be provided via a 'control panel' interface to 'red-flag' students that have not completed all these attempts, so that they may be individually counselled about their progress. This can be used to ensure that full coverage of the learning opportunities are achieved for each student. It can also be used to identify modules or scenarios that students are obviously struggling with, as they either fail to attain significant results, or the number of attempts appears to be higher than with other modules. This may propel dedicated instructors to re-visit these situations in a classroom environment to further improve the student capabilities in these areas.

A final benefit for instructors is preventing the existence of 'one-use cases'. Many case studies have a short lifespan in contemporary educational environments. It is difficult for an instructor to use the same case semester after semester, as feedback provided to one cohort of Post-Experience Assessment. Using the nDiVE approach there are multiple, on-going assessments to aid the learner. These can be broken down into two main types of assessments: peer- and self-assessment as formative assessments and assessment by an instructor as a summative assessment. All of these experiences can be recorded and archived for further moderation exercises if required by staff or the learning institution.

There are constant embedded formative assessments of the student learning and progress. This is accomplished through both peer- and self-directed assessment. Working individually in nDiVE, a student is able to use the pre-scripted bots to interact with the environment and record results using the Machinima recording capabilities. This enables interaction with the environment in a way that a record is maintained for further study later. This enables data and results to be stored, or used to provide the user with instant feedback on their capabilities within that scenario. Peers and other users are also able to record and observe the user interactions with the environment and provide feedback in a structured environment. Thus, users 
are able to achieve instant feedback with automated scenarios. This can be regarded as formative assessment and the provision of feedback.

Acrucial component of post-experience assessment is the summative engagement with instructors. Trained instructors will be available to review key recordings and observe key experiences. They will then be positioned to create or select a new scenario for the user to work through, enabling a summative evaluation of students' capabilities.

\section{CONCLUSION}

Training for workers has frequently taken place with the aid of simulations of various types, whether they are extremely authentic (actually using the exact equipment that would be used in the working environment) or less authentic (using board-based management education games like the Beer Game); or somewhere in-between (such as using a computerised flight simulator to train pilots). What we propose is an integrated environment, capable of displaying multiple dimensions for the user, to aid their education within the discipline of logistics and supply chain management. This approach is beneficial as it reduces costs of perceiving an entire supply chain; it allows students to immediately see impacts of actions that otherwise would occur months later or even on different continents and thus not apparent while also allowing safe and relatively low-cost training to occur with no possibility of damage to the learners or the working environment or equipment. Multiple assessment strategies may be employed, over the various components, to enhance learning. Students are able to examine scenarios from different perspectives, rather than a fixed perspective employed in traditional learning environments, and this can be enhanced through team-based activities and scenarios.

While there are simulations that can be created to aid supply chain education, they tend to be non-connected and act in isolation from each other. We propose to connect such disconnected modules into a holistic system, accurately reflecting reality, while still compressing of timeand-space. nDiVE acts as an interface with this training environment, allowing users to go deeper into or to zoom out to gain greater perspective. It is clear that this represents a shift away from narrowly-focused function-specific simulators. Such training environments have not previously been practicable in a broad industry, like the supply chain industry, where there are so many differences between sectors and firms. The increased authenticity that $\mathrm{nDiVE}$ allows students to experience is a supplement to existing pedagogical models used in a supply chain programmes. Instruction, text books, and cases, can be added to using the simulation; even site visits can add an air of authenticity that nDiVE is hard-pressed to replace. Even industry engagement is maintained, as part of the simulation development.

A further benefit of the nDiVE environment is the modular design. Thus, if elements of the supply chain model remain incomplete, there is still the opportunity for the created modules to be interlinked effectively. This means that an incomplete project, failing to meet the full scope planned in advance, may still have valuable and useful deliverables. If phases of the supply chain remain unmodelled, these can be represented by an automatic 'black box' within the environment, allowing the rest of the environment, even if incomplete, to still be useable for training purposes.

Managing a supply chain is, in some way, akin to piloting an aircraft. When there is an experienced expert in control, we can rest easily as we can be reassured that if there is a problem, they will know how to fix it. Unfortunately, there are numerous cases where supply chain managers have been unprepared to cope with exceptional circumstances, which have had impacts beyond their control or expectations. Pilots are required to have extensive piloting experience, working in a simulator, experiencing new and dangerous situations and developing the skills to manage 
these situations and in light of passenger safety. Our premise is that supply chain managers, given the dangerous working environment, the complexity of the scenarios, physical dispersion of supply chains, and the ripple effect amplifying errors or mistakes along the supply chain, should also be trained extensively in a simulated, virtual environment. Such training would allow them to experience extreme situations, understand complex supply chain relationships, and manage to overcome challenges in the chain in such a way as to minimise the impact on the environment or stakeholders. Just as when boarding a plane we feel comfortable and reassured that our pilots will get us to our destination safely, perhaps one day society will feel comfortable knowing that there are competent, well-trained, supply chain managers that have been trained to deal with a range of complex issues and situations.

\section{Implications}

The nDiVE environment may be used to increase temporal and spatial awareness of the possible consequences of actions in the working environment. This implies that there is significant value to using nDiVE in working environments, particularly those employing heavy/dangerous machinery or those involved in complex supply chains.

In the educational setting, it is not clear whether the use of nDiVE would reduce training times, but it should improve the effectiveness of the training received. It may also open up new opportunities for education and we believe that such an integrated system would be a valuable foundation for supplementing existing pedagogical approaches in supply chain management education.

\section{Limitations}

The nDiVE environment has yet to be realised. Components have been created but work still needs to be completed to join these together in the integrated nDiVE environment. One key barrier to improved authenticity is the control of the avatar within the environment; current technology employs the use of keyboard, mouse, touch-pointers, which are unnatural and are not conducive to effective learning. Future technology may involve an integrated use of 3D goggles and devices for gesture-recognition, enabling an increasingly user-friendly and natural interface with the nDiVE environment and, with it, an increasingly authentic experience for the user.

\section{REFERENCES}

Bailey, R., \& Garner, M. (2010). Is the feedback in higher education assessment worth the paper it is written on? Teachers' reflections on their practices. Teaching in Higher Education, 15(2), 187-198. doi:10.1080/13562511003620019.

Bajdor, P., \& Dragolea, L. (2011). The gamification as a tool to improve risk management in the enterprise. Annales Universitatis Apulensis Series Oeconomica, 13(2), 574-583.

Boerger, F., \& Tietgens, H. (2013). TÜV NORD in 3D: Avatars at work: From Second Life to the Web 3D. In Hebbel-Segger, A., Reiners, T., \& Schäfer, D. (Eds.), Alternate realities: Emerging technologies in education and economics. Springer Verlag.

Buckridge, M., \& Guest, R. (2007). A conversation about pedagogical responses to increased diversity in university classrooms. Higher Education Research \& Development, 26(2), 133-146. doi:10.1080/07294360701310771.

Burke, B. (2011). Innovation insight: Gamification adds fun and innovation to inspire engagement (Gartner Report G00226393). Retrieved from http://my.gartner.com/portal/server.pt?open $=51$ $2 \&$ objID $=260 \&$ mode $=2 \&$ PageID $=3460702 \& \mathrm{r}$ esId=1879916 
Burmester, A., Burmester, F., \& Reiners, T. (2008). Virtual environment for immersive learning of container logistics (with). In Proceedings of World Conference on Educational Multimedia, Hypermedia \& Telecommunications (ED-MEDIA 2008), Vienna, Austria (pp. 5843-5852).

Constable, G. (2008). Virtual worlds: A short introduction to Second Life. Retrieved June 1,2012, from http://au.youtube.com/watch?v=5ME2FwjjPf8

Cotter, J., Forster, J., \& Sweeney, E. (2009). Supply chain learning - The role of games. Supply Chain Perspectives, the Journal of the National Institute for Transport and Logistics, 10(3).

De Vita, G., \& Case, P. (2003). Rethinking the internationalisation agenda in UK higher education. Journal of Further and Higher Education, 27(4), 383-398. doi:10.1080/0309877032000128082.

Deloitte. (2012). Tech trends 2012: Elevate IT for digital business. Retrieved from http:// www.deloitte.com/assets/Dcom-UnitedStates/ Local\%20Assets/Documents/us_cons_techtrends2012_013112.pdf

Do, K. (2006). Experiential education: Beyond the classroom. In Proceedings of the Evaluations and Assessment: Enhancing Student Learning, Curtin University of Technology, Perth, Australia.

Dreher, H. (2006). Interactive on-line formative evaluation of student assignments. Journal of Issues in Informing Science and Information Technology, 3, 189-197.

Feng, K., \& Ma, G. (2008). Learning supply chain management with fun: An online simulation game approach. California Journal of Operations Management, 6(1), 41-48.

Ferns, S. (2011). Allocating academic workload for student consultation assessment and feedback. In Proceedings of the Australian Technology Network Assessment Conference 2011, Perth, Western Australia.
Gartner Research. (2011). Gartner technology hype cycle. Retrieved from http://www.gartner. com/hc/images/215650_0001.gif

Groh, F. (2012). Gamification: State of the art definition and utilization. In Proceedings of the 4th Seminar on Research Trends in Media Informatics, Ulm University, Ulm, Germany.

Gurin, P., Dey, E., Hurtado, S., \& Gurin, G. (2002). Diversity and highereducation: Theory and impact on educational outcomes. Harvard Educational Review, 72(3), 330-367.

Hanna, M. D. (2000). Touring a supply chain with students: Pedagogical and practical considerations. Production and Operations Management, 9(2), 203-211. doi:10.1111/j.1937-5956.2000. tb00334.x.

Heineke, J. N., \& Meile, L. C. (1995). Games and exercises for operations management: Hands-on learning activities for basic concepts and tools. Englewood Cliffs, NJ: Prentice Hall.

Herrington, A., \& Herrington, J. (2006). Authentic learning environments in higher education. Hershey, PA: IGI Global.

Herrington, J., Reeves, T. C., \& Oliver, R. (2010). A guide to authentic e-learning. New York, NY: Routledge.

Hogan, J. M., Carlson, J. G., \& Dua, J. (2002). Stressors and stress reactions among university personnel. International Journal of Stress Management, 9(4), 289-309. doi:10.1023/A:1019982316327.

Holt, D., Mackay, D., \& Smith, R. (2003). Educating for professional capability in the field of information technology: Integrating industrybased learning with the academic curriculum. In Proceedings of the 13th World Conference on Cooperative Education, Rotterdam, The Netherlands. 
Ibabe, I., \& Jauregizar, J. (2010). Online selfassessment with feedback and metacognitive knowledge. Higher Education, 59(2), 243-258. doi:10.1007/s10734-009-9245-6.

IEEE VW Standard Working Group Group. (2012). Virtual worlds. Retrieved from http://www. metaversestandards.org/index.php?title=Virtual_ Worlds\#Virtual_Worlds:_Types_and_Definitions

Kolb, D. A. (1984). Experiential learning: Experience as the source of learning and development. Englewood Cliffs, NJ: Prentice-Hall.

Krathwohl, D. R. (2002). A revision of Bloom's taxonomy: An overview. Theory into Practice, 41(4), 212. doi:10.1207/s15430421tip4104_2.

Kuijpers, R. P. (2009). Supply chain risk management game. (Unpublished master's thesis). Delft University of Technology, Netherlands.

KZero. (2009). KZero projects massive growth in Virtual World revenue. Retrieved from http://www. theimaginationage.net/2009/09/kzero-projectsmassive-growth-in.html

Lainema, T., \& Hilmola, O.-P. (2005). Learn more, better and faster: Computer-based simulation gaming of production and operations. International Journal on Business Performance Management, 7(1), 34-59. doi:10.1504/IJBPM.2005.006242.

Landers, R. N., \& Callan, R. C. (2011). Casual social games as serious games: The psychology of gamification in undergraduate education and employee training. In Ma, M., Oikonomou, A., \& Jain, L. C. (Eds.), Serious games and edutainment applications (pp. 399-423). London, UK: Springer London. doi:10.1007/978-1-4471-2161-9_20.

Lee, H. L., Padmanabhan, V., \& Wang, S. (1997). The bullwhip effect in supply chains. Sloan Management Review, 38(3), 93-102.

Lombardi, M. M. (2007). Authentic learning for the 21 st century: An overview (ELI Report No. 1). Boulder, CO: EDUCAUSE Learning Initiative.
MacCarron, C. (2006). Confined space fatalities. Unpublished doctoral dissertation, Edith Cowan University, Joondalup, Australia.

Martin, Y. M., \& Karmel, T. (2002). Expansion in higher education during the 1990s: Effects on access and student quality. Canberra, Australia: Department of Education, Science and Training.

Maruyama, G., Moreno, J. F., Gudeman, R. H., \& Marin, P. (2000). Does diversity make a difference? Three research studies on diversity in college classrooms. Washington, DC: American Council on Education and American Association of University Professors.

Nicol, D. J., \& Macfarlane-Dick, D. (2006). Formative assessment and self-regulated learning: A model and seven principles of good feedback practice. Studies in Higher Education, 31(2), 199-218. doi:10.1080/03075070600572090.

Page, J. (2004). Implementing lean manufacturing techniques: Making your system lean and living with it. Cincinnati, $\mathrm{OH}$ : Hanser Gardner Publications.

Peterson, S. (2012). Gamification market to reach $\$ 2.8$ billion in 2016. Gameindustry International. Retrieved from http://www.gamesindustry.biz/ articles/2012-05-21-gamification-market-toreach-USD2-8-billion-in-2016

Porth, S. J. (1997). Management education goes international: A model for designing and teaching a study tour course. Journal of Management Education, 21(2), 190-199. doi:10.1177/105256299702100204.

Radoff, J. (2011). Game on: Energize your business with social media games. Indianapolis, IN: Wiley.

Revell, A., \& Wainwright, E. (2009). What makes lectures 'unmissable'? Insights into teaching excellence and active learning. Journal of Geography in Higher Education, 33(2), 209-223. doi:10.1080/03098260802276771. 
Ricketts, C., \& Wilks, S. J. (2002). Improving student performance through computer-based assessment: Insights from recent research. Assessment \& Evaluation in Higher Education, 27(5), 475-479. doi:10.1080/0260293022000009348.

Rosenberg, M. J. (2006). Beyond e-learning. San Francisco, CA: Pfeiffer.

SAP. (2012). Gamification not just for kids. Retrieved from http://www.sap.com/asset/ index.epx?id=438d1d10-a5ed-453a-8ad4d5480c584f2c\&name=Gamification-Not-Justfor-Kids

Schwartz, F., \& White, K. (2000). Making sense of it all: Giving and getting online course feedback. In White, K. W., \& Weight, B. H. (Eds.), The online teaching guide: A handbook of attitudes, strategies, and techniques for the virtual classroom (pp. 57-72). Boston, MA: Allyn \& Bacon.

Shute, V. J. (2008). Focus on formative feedback. Review of Educational Research, 78(1), 153-189. doi:10.3102/0034654307313795.

Slone, D. J. (2009). A methodology for measuring usability evaluation skills using the constructivist theory and the second life virtual world. Journal of Usability Studies, 4(4), 178-188.

Sterman, J. D. (1989). Modeling managerial behavior: Misperceptions of feedback in a dynamic decision making experiment. Management Science,35(3),321-339. doi:10.1287/mnsc.35.3.321.

Taras, M. (2003). To feedback or not to feedback in student self-assessment. Assessment \& Evaluation in Higher Education, 28(5), 549-565. doi:10.1080/02602930301678.
Terenzini, P. T., Cabrera, A. F., Colbeck, C. L., Bjorklund, S. A., \& Parente, J. M. (2001). Racial and ethnic diversity in the classroom: Does it promote student learning? The Journal of Higher Education, 72(5), 509-531.doi:10.2307/2672879.

Volet, S. E., \& Ang, G. (1998). Culturally mixed groups on international campuses: An opportunity for inter-cultural learning. Higher Education Research \& Development, 17(1), 5-23. doi:10.1080/0729436980170101.

Wood, L., \&Lu, Q. (2008). Process managementin high tech New Zealand firms. International Journal of Innovation and Technology Management, 5(3),259-278. doi:10.1142/S0219877008001424.

Wood, L. C., \& Reefke, H. (2010). Working with a diverse class: Reflections on the role of team teaching, teaching tools and technological support. In Proceedings of the IADIS International Conference on International Higher Education (IHE 2010), Perth, Australia.

Wriedt, S., Reiners, T., \& Ebeling, M. (2008). How to teach and demonstrate topics of supply chain management in Virtual Worlds. In Proceedings of the ED-MEDIA World Conference on Educational Multimedia, Hypermedia \& Telecommunications, Vienna, Austria.

Zhang, C., Sillitoe, J., \& Webb, J. (1999). Valuing cultural diversity in student learning: the academic adjustment experiences of international Chinese students. In Proceedings of the HERDSA Annual International Conference, Melbourne, Australia. 